\title{
Secondary syphilis with atypical rash and hemoptysis in a man with HIV co-infection
}

\author{
Quinlan Richert MD, Jennifer Campbell MD, Yoav Keynan MD PhD
}

Cite as: CMAJ 2019 December 16;191:E1383. doi: 10.1503/cmaj.190495

See related article at www.cmaj.ca/lookup/doi/10.1503/cmaj.191075

A 37-year-old man with HIV infection (CD4+ cell count 706 cells/ $\mu \mathrm{L}$, viral load undetectable) presented with a 3-month history of cough, pharyngitis, low-grade fevers and dark black hemoptysis. A rash had also developed, originating at the left commissure of the mouth, that had spread to the forehead, back and thighs over the 3-month period; the rash was not painful or pruritic. The patient, who engages in receptive anal intercourse, had recently had unprotected sexual contact with an individual with an uncertain history of syphilis. The patient had received treatment 3 years earlier for syphilis.

On examination, we noted a well-circumscribed and erythematous papular-nodular rash on his forehead, back and thighs, sparing his palms and soles (Figure 1; Appendix 1, available at www. cmaj.ca/lookup/suppl/doi:10.1503/cmaj.190495/-/DC1). Computed tomography of the chest was normal. The remainder of the hemoptysis work-up (including sputum acid-fast bacilli testing, hemoglobin and platelet count) were normal, as were liver enzyme studies. The patient's kidney function was mildly reduced.

We made a presumptive diagnosis of secondary syphilis with atypical papular-nodular skin lesions and pulmonary involvement. Empiric treatment for secondary syphilis was initiated with 2.4 million units of intramuscular penicillin $\mathrm{G}$ benzathine. Forty-eight hours later, the rash had substantially receded and the hemoptysis had resolved. All systemic symptoms completely resolved within 5 days. On the return of positive nontreponemal (rapid reactive plasma reagin 1:32 at a follow-up appointment) and treponemal (Venereal Disease Research Laboratory test [VDRL] 1:64 at the original appointment) serology, and a skin biopsy showing a mixed perivascular-interstitial infiltrate rich in plasma cells, the diagnosis was confirmed. In follow-up, the VDRL titre was 1:32 at 4 months, 1:4 at 7 months and 1:2 at 1 year.

Atypical presentations of syphilis are more common in individuals with HIV infection, but pulmonary involvement is uncommon. Only 25 cases were identified in our literature search, and as of 2006, only 6 cases were reported to have co-occurred with HIV. ${ }^{1}$ However, given the increasing incidence of syphilis in Canada and the United States, ${ }^{2}$ the number of cases has probably increased.

The diagnosis of pulmonary syphilis is based on criteria proposed by Coleman and colleagues in 1983: radiographic evidence of pulmonary involvement; historical, physical examination and serological findings typical of syphilis; the exclusion of other pulmonary disease; and response to antisyphilis therapy. ${ }^{3}$

Although there were no radiographic findings in our case, this is likely because the rapid response to therapy obviated the need

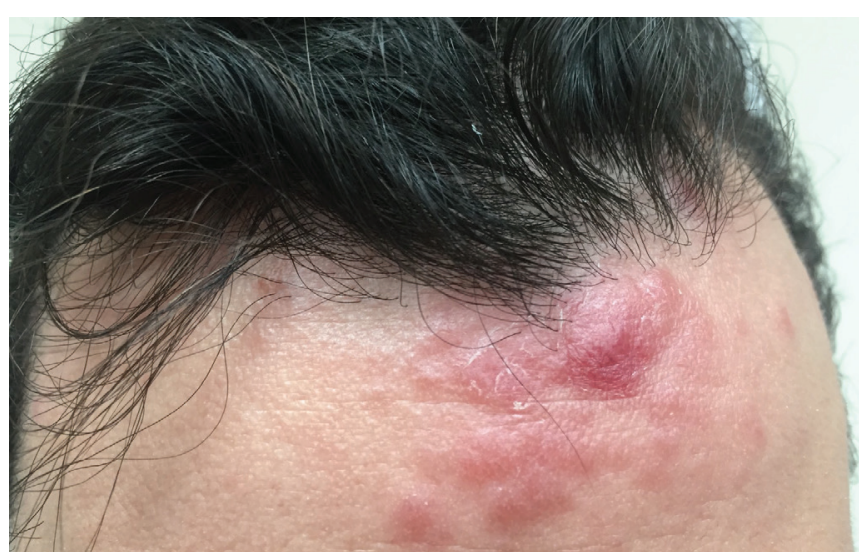

Figure 1: Papular-nodular rash on the forehead of a 37-year-old man with a history of HIV infection and previously treated syphilis, presenting with fever and hemoptysis, consistent with secondary syphilis with atypical rash and pulmonary involvement.

for repeated imaging. Urgent bronchoscopy was considered, but ultimately cancelled. As such, the diagnosis of pulmonary involvement was based on serological evidence of syphilis infection, absence of an alternative explanation for the hemoptysis, and resolution of symptoms with appropriate therapy.

\section{References}

1. David G, Perpoint T, Boibieux A, et al. Secondary pulmonary syphilis: report of a likely case and literature review. Clin Infect Dis 2006;42:e11-5.

2. Choudhri Y, Miller J, Sandhu J, et al. Infectious and congenital syphilis in Canada, 2010-2015. Can Commun Dis Rep 2018;44:43-8.

3. Coleman DL, McPhee S, Ross T, et al. Secondary syphilis with pulmonary involvement. West J Med 1983;138:875-8.

\section{Competing interests: None declared.}

This article has been peer reviewed.

The authors have obtained patient consent.

Affiliations: Department of Internal Medicine (Richert, Keynan), Max Rady College of Medicine, University of Manitoba; Nine Circles Community Health Centre (Campbell); Manitoba HIV Program (Campbell, Keynan); Section of Medical Microbiology and Infectious Diseases (Keynan), Max Rady College of Medicine, University of Manitoba, Winnipeg, Man.

Acknowledgement: The authors thank Dr. Laurie Ireland for her insights and contributions to this article.

Correspondence to: Quinlan Richert, umricheq@myumanitoba.ca 